\title{
Formulation Development and in vitro Evaluation of Drug Release Kinetics from Sustained Release Aceclofenac Matrix Tablets using Hydroxypropyl Methyl Cellulose
}

\author{
Abul Kalam Lutful Kabir ${ }^{1}$, Shimul Halder ${ }^{1}$, Madhabi Lata Shuma ${ }^{2}$ \\ and Abu Shara Shamsur Rouf ${ }^{1}$
}

\author{
${ }^{1}$ Department of Pharmaceutical Technology, University of Dhaka, Dhaka-1000, Bangladesh \\ ${ }^{2}$ Department of Pharmacy, Stamford University, 51 Siddeswari Road, Ramna, Dhaka-1217, Bangladesh
}

\begin{abstract}
The objective of the present study was to develop a once-daily sustained release matrix tablet of Aceclofenac using hydroxypropyl methyl cellulose (Methocel K 100M CR) as release controlling factor and to evaluate drug release parameters as per various release kinetic models. The tablets were prepared by direct compression method. The powder blends were evaluated for angle of repose, loose bulk density, tapped bulk density, compressibility index, total porosity and drug content etc. The tablets were subjected to thickness, weight variation test, drug content, hardness, friability and in vitro release studies. The in vitro dissolution study was carried out for 24 hours using United States Pharmacopoeia (USP) 22 paddle-type dissolution apparatus in phosphate buffer (pH 7.4). The powder blends showed satisfactory flow properties, compressibility index and drug content etc. All the tablet formulations showed acceptable pharmacotechnical properties and complied with pharmacopoeial specifications. The results of dissolution studies indicated that the formulation F-3 (40\% Methocel K100M CR of total weight of tablet) could extend the drug release up to 24 hours and the total release pattern was very close to the theoretical release profile. By comparing the dissolution profiles with the originator brand of Arrestin SR, the formulation F-3 exhibited drug release profile like originator brand. From this study, a decrease in release kinetics of the drug was observed by increasing the polymer concentration. Kinetic modeling of in vitro dissolution profiles revealed the drug release mechanism ranges from diffusion controlled or Fickian transport to anomalous type or non-Fickian transport, which was only dependent on the type and amount of polymer used. The drug release followed both diffusion and erosion mechanism in all cases. The drug release from the formulation (F-3) was satisfactory after 3 months storage in $40^{\circ} \mathrm{C}$ and $75 \%$ RH. Besides, this study explored both of the optimum concentration and effect of polymer(s) on Aceclofenac release pattern from the tablet matrix for 24 hour period. The matrix tablet of Aceclofenac using HPMC with molecular weight of $\mathrm{K} 100 \mathrm{M}$ controlled the drug release effectively for 24 hours; hence the formulation can be considered as a once daily sustained release tablet of Aceclofenac in order to improve patient compliance.
\end{abstract}

Keywords: Aceclofenac, sustained release, once daily, HPMC, direct compression.

\section{INTRODUCTION}

Aceclofenac, a phenyl acetic acid derivative, is one of the emerging nonsteroidal antinflammatory drugs (NSAIDs) and considered to be the first line drugs in the symptomatic treatment of rheumatoid arthritis, osteoarthritis and ankylosing spondylitis. ${ }^{1}$ It is a newer derivative of diclofenac having less gastrointestinal complications. The mode of action of

Correspondence to: Shimul Halder

Cell: $+88-01716599577$

E-mail: sk_halder_85@yahoo.com

Dhaka Univ. J. Pharm. Sci. 11(1): 37-43, 2012 (June)
Aceclofenac is largely based on the inhibition of prostaglandin synthesis by inhibiting the enzyme cyclooxygenase. The successful treatment of arthritis depends on the maintenance of effective drug concentration level in the body for which a constant and uniform supply of drug is desired. ${ }^{2}$ Aceclofenac has a short biological half life (about 4 hours) and the usual oral dosage regimen is $100 \mathrm{mg}$ taken twice daily. It is a weak acid ( $\mathrm{pKa}=4.7$ ) practically insoluble in water and acidic environment but highly permeable (class-2) according to the Biopharmaceutical Classification System (BCS). The oral 
absorption is uniform, rapid and complete with a bioavailability of nearly $100 \%$ and an elimination halflife of 2-4 h. Once daily sustained release formulations are required to reduce the frequency of dose and to improve patient compliance. ${ }^{3}$ The most common method of modulating drug release is to include it in a matrix system. ${ }^{4}$ Because of their flexibility, hydrophilic polymer matrix systems are widely used in oral controlled drug delivery to obtain a desirable drug release profile, cost effectiveness, and broad regulatory acceptance. ${ }^{5}$ Among the hydrophilic polymers, various grades of hydroxypropyl methyl cellulose (HPMC) are frequently used because of its nontoxic nature, easy compression, swelling properties and accommodation to high levels of drug loading. ${ }^{6}$ Additionally, HPMC is a $\mathrm{pH}$ independent material and hence drug release from HPMC matrix formulations is generally independent of physiological variables of GIT. ${ }^{7}$

Oral sustained release dosage form by direct compression technique is a very simple approach in the pharmaceutical arena for its ease, compliance, faster production and avoidance of hydrolytic or oxidative reactions which occur during processing of dosage forms. ${ }^{8}$ Sustained or controlled drug delivery can be achieved when a drug is embeded within a polymer matrix that may be either natural or semisynthetic or synthetic in nature. ${ }^{9}$ However the polymer has to be judiciously combined with the drug and other excipients in such a way that the active agent is released from the matrix in a predetermined rate for the desired time period. There are a number of techniques applied in the formulation and manufacturing of sustained release dosage form. But, the matrix tablet prepared by direct compression has attracted much attention due to its technological simplicity in comparison with other controlled release systems. ${ }^{10}$

\section{MATERIALS AND METHODS}

Materials. The following materials were used in the present study: Aceclofenac (Square pharmaceuticals, Bangladesh, potency: 99.91\%); Methocel K100M CR (Dow Chemical Company,
Midland, MI, USA); Microcrystalline Cellulose (Avicel PH 101) (Zhejiang Tianxin Pharmaceuticals Ltd.), Polyvinyl Pyrrolidone (Povidone K30)(colorcon,Bangladesh), Colloidal Anhydrous Silica (Aerosil 200) (Hanau Chemicals Ltd.) and Magnesium Stearate (Hanau Chemicals Ltd., Japan).

Arrestin SR (Originator Brand, Maneesh pharma).

Solvents and reagents: Distilled water, Potassium dihydrogen phosphate (Merck, Germany); Sodium hydroxide (Merck, Germany).

Equipments: Single punch tablet press (Shanghai-Tianhe Pharmaceutical Machinery Company); UV spectrophotometer (Shimadzu, Japan); Digital pH meter (Hanch Company, USA); Electronic hardness tester (Ereweka, Germany); Tablet dissolution tester (Electrolab, India); Electronic balance.

Preparation of matrix tablet. The tablet was prepared by simple blending of the active ingredient with the polymer and other excipients followed by direct compression (Table 1). 50 tablets were prepared for each formulation. Altogether, seven formulations were made and coded as F-1,F-2 ...F-7. Properly weighed Methocel, Povidone K-30, Avicel PH 101, Magnesium stearate, Aerosil and the active ingredient were blended in a laboratory designed small drum blender machine for 30 minutes to ensure thorough mixing and phase homogenization ${ }^{11}$.

Physical evaluation of powder blends of tableting materials. The powder materials were evaluated for angle of repose, loose bulk density, tapped bulk density, compressibility index, total porosity, and drug content.

Bulk density: $L B D$ (Loose Bulk Density) and $T B D$ (Tapped Bulk Density) were determined by taking $2 \mathrm{~g}$ of powder from each formula, previously lightly shaken to break any agglomerates and pouring into a $10 \mathrm{ml}$ measuring cylinder. After the initial volume was observed, the cylinder was allowed to fall under its own weight onto a hard surface from the height of $2.5 \mathrm{~cm}$ at 2 second intervals. The reading of tapping was continued until no further change in volume was noted. Using the following equation $\angle B D$ and $T B D$ were calculated: 
$L B D=$ Weight of the powder / initial volume of the packing.

$T B D=$ Weight of the powder / Tapping volume of the packing.

Compressibility index: The compressibility index of the powder blends was determined by Carr's compressibility index:

Carr's index $(\%)=\{(T B D-L B D) \times 100\} / T B D$

Total porosity: Total porosity was determined by measuring the volume occupied by a selected weight of powder $\left(V_{\text {bulk }}\right)$ and the true volume of powder blends (the space occupied by the powder exclusive of spaces greater than the intermolecular space $(V)$ :

Porosity $(\%)=V_{\text {bulk }}-V / V_{\text {bulk }} \times 100$

Angle of repose: The angle of repose of powder blends was determined by the funnel method. The accurately weighed powder blends were taken in a funnel. The height of the funnel was adjusted in such a way that the tip of the funnel just touched the apex of the heap of the powder blends. The powder blends were allowed to flow through the funnel freely onto the surface. The diameter of the powder cone was measured and angle of repose was calculated using the following equation.

Angle of Repose $\theta=\tan ^{-1} h / r$

Where, $h=$ Height of the powder cone.

$r=$ Radius of the powder cone

Physical evaluation of Aceclofenac matrix tablet .The prepared tablets were evaluated for their thickness, weight variation, hardness, friability, and drug content.

In vitro dissolution study. The release study was carried out for 24 hours using USP 22 paddletype dissolution apparatus in buffer $(\mathrm{pH} 7.4)$ at 100 $\mathrm{rpm}$ maintaining the temperature at $37 \pm 0.5^{\circ} \mathrm{C}$. A 10 $\mathrm{ml}$ samples were collected from each vessel at 1, 2, 4, $6,8,10,12,16,20$ and 24 hour interval and analyzed spectrophotometrically for Aceclofenac at $275 \mathrm{~nm}$. The withdrawn sample was immediately replaced by equal volume of fresh buffer.

Data analysis: To analyze the in vitro release data various kinetic models were used to describe the release kinetics. The zero order rate Eq. (1) describes the systems where the drug release rate is independent of its concentration. The first order Eq. (2) describes the release from system where release rate is concentration dependent. Higuchi (1963) described the release of drugs from insoluble matrix as a square root of time dependent process based on Fickian diffusion Eq. (3). The Hixson-Crowell cube root law Eq. (4) describes the release from systems where there is a change in surface area and diameter of particles or tablets.

$$
C=k_{0} t
$$

Where, $\mathrm{K}_{0}$ is zero-order rate constant expressed in units of concentration/time and $\mathrm{t}$ is the time.

$$
\log C_{0}-\log C=k t / 2.303
$$

Where, $\mathrm{C}_{0}$ is the initial concentration of drug and $\mathrm{K}$ is first order constant.

$$
Q=K t_{1 / 2}
$$

Where, $\mathrm{K}$ is the constant reflecting the design variables of the system.

$$
Q_{0}{ }^{1 / 3}-Q_{t}{ }^{1 / 3}=K_{H C} t
$$

Where, Qt is the amount of drug released in time $\mathrm{t}, \mathrm{Q}_{0}$ is the initial amount of the drug in tablet and $\mathrm{K}_{\mathrm{HC}}$ is the rate constant for Hixson-Crowell rate equation.

The following plots were made: cumulative \% drug release vs. time (zero order kinetic model); log cumulative of $\%$ drug remaining vs. time (first order kinetic model); cumulative $\%$ drug release vs. square root of time (higuchi model) log cumulative \% drug release vs. log time (korsmeyer model) and cube root of drug \% remaining in matrix vs. time (Hixson Crowell cube root law).

Mechanism of drug release. Korsmeyer et al (1983) derived a simple relationship which described drug release from a polymeric system Eq. (5). To find out the mechanism of drug release, first $60 \%$ drug release data was fitted in Korsmeyer-Peppas model:

$\mathrm{Mt} / \mathrm{M} \infty=\mathrm{Kt}^{\mathrm{n}}$

Where Mt / M $\infty$ is fraction of drug released at time $\mathrm{t}, \mathrm{k}$ is the rate constant and $\mathrm{n}$ is the release exponent. The $\mathrm{n}$ value is used to characterize 
different release mechanisms as given in the following table for cylindrical shaped matrices. ${ }^{12}$

\section{RESULTS AND DISCUSSION}

In the present study, an attempt has been taken to develop "once daily" sustained release tablets of Aceclofenac by direct compression method using Methocel $\mathrm{K} 100 \mathrm{M} \mathrm{CR}$ as the rate retarding agent (Table 1). Methocel K100M CR was increased in the proposed formulations F-1 to F-7 in order to evaluate the amount of polymer required to provide desired release rate for 24 hour period. The powder blends of proposed formulations (F-1 to F-7) were evaluated for $\mathrm{LBD}$, TBD, compressibility index, total porosity, angle of repose and drug content (Table 3). The results of $\mathrm{LBD}$ and TBD ranged from $0.40 \pm 0.03$ to $0.52 \pm 0.02$ and $15.25 \pm 0.01$ to $27.14 \pm 0.01$ respectively. The results of compressibility index (\%) ranged from $15.25 \pm 0.01$ to $27.78 \pm 0.03$. The results of angle of repose ranged from $20.05 \pm 0.02$ to 25.05 $\pm 0.02\left(^{\circ}\right)$. The percentage porosity values of the powder blends ranged from $23.0 \pm 0.01$ to $26.25 \pm$ $0.06 \%$ indicating that the packing of the powder blends may range from close to loose packing and also further confirming that the particles are not of greatly different sizes. The drug content in a weighed amount of powder blends of all formulations ranged

Table 1. Proposed formulations of Aceclofenac SR matrix tablets containing Methocel K 100M CR.

\begin{tabular}{lccccccc}
\hline Ingredients (mg) & \multicolumn{7}{c}{ Formulations } \\
\cline { 2 - 8 } & F-1 & F-2 & F-3 & F-4 & F-5 & F-6 & F-7 \\
\hline Aceclofenac & 200 & 200 & 200 & 200 & 200 & 200 & 200 \\
Methocel K100M CR & 60 & 70 & 80 & 90 & 100 & 110 & 120 \\
Povidone K-30 & 4 & 4 & 4 & 4 & 4 & 4 & 4 \\
Avicel PH 101 & 140 & 130 & 120 & 110 & 100 & 90 & 80 \\
Aerosil 200 & 2.5 & 2.5 & 2.5 & 2.5 & 2.5 & 2.5 & 2.5 \\
Magnesium Stearate & 3.5 & 3.5 & 3.5 & 3.5 & 3.5 & 3.5 & 3.5 \\
Total weight/Tablet (mg) & 410 & 410 & 410 & 410 & 410 & 410 & 410 \\
\hline
\end{tabular}

Table 2. Diffusion exponent and solute release mechanism for cylindrical shape matrices.

\begin{tabular}{ll}
\hline Diffusion exponent $(\mathrm{n})$ & Overall solute diffusion mechanism \\
\hline 0.45 & Fickian diffusion \\
$0.45<\mathrm{n}<0.89$ & Anomalous (non-Fickian) diffusion \\
0.89 & Case-II transport \\
$\mathrm{n}>0.89$ & Super case-II transport \\
\hline
\end{tabular}

Table 3. Physical properties of powder blends (F-1 to F-7).

\begin{tabular}{|c|c|c|c|c|c|c|}
\hline Tablet & $\begin{array}{c}\text { Angle of repose } \\
\left(\left(^{\circ}\right)\right.\end{array}$ & $\begin{array}{l}\text { Loose Bulk Density } \\
\text { (LBD) }(\mathrm{g} / \mathrm{ml})\end{array}$ & $\begin{array}{l}\text { Tapped Bulk Density } \\
\text { (TBD) }(\mathrm{g} / \mathrm{ml})\end{array}$ & $\begin{array}{l}\text { Compressibility } \\
\text { Index }(\%)\end{array}$ & $\begin{array}{c}\text { Total Porosity } \\
(\%)\end{array}$ & $\begin{array}{c}\text { Drug Content } \\
(\%)\end{array}$ \\
\hline F-1 & $20.15 \pm 0.01$ & $0.51 \pm 0.03$ & $0.50 \pm 0.02$ & $15.25 \pm 0.01$ & $25.45 \pm 0.02$ & $99.45 \pm 0.02$ \\
\hline $\mathrm{F}-2$ & $25.05 \pm 0.02$ & $0.45 \pm 0.01$ & $0.59 \pm 0.03$ & $22.15 \pm 0.02$ & $25.98 \pm 0.05$ & 99.210 .06 \\
\hline $\mathrm{F}-3$ & $22.55 \pm 0.05$ & $0.44 \pm 0.05$ & $0.55 \pm 0.04$ & $26.14 \pm 0.02$ & $25.21 \pm 0.03$ & $97.55 \pm 0.02$ \\
\hline F-4 & $24.25 \pm 0.01$ & $0.46 \pm 0.03$ & $0.62 \pm 0.05$ & $23.00 \pm 0.04$ & $24.36 \pm 0.02$ & $99.00 \pm 0.03$ \\
\hline F-5 & $24.15 \pm 0.15$ & $0.52 \pm 0.02$ & $0.70 \pm 0.03$ & $27.78 \pm 0.03$ & $23.0 \pm 0.01$ & $99.45 \pm 0.05$ \\
\hline F-6 & $22.15 \pm 0.04$ & $0.45 \pm 0.02$ & $0.58 \pm 0.05$ & $24.14 \pm 0.01$ & $26.25 \pm 0.06$ & $98.25 \pm 0.08$ \\
\hline $\mathrm{F}-7$ & $20.05 \pm 0.02$ & $0.40 \pm 0.03$ & $0.58 \pm 0.02$ & $25.56 \pm 0.02$ & $26.0 \pm 0.015$ & $97.35 \pm 0.08$ \\
\hline
\end{tabular}

from $97.35 \pm 0.08$ to $99.45 \pm 0.05 \%$. All these results indicate that the powder blends possess satisfactory flow properties, compressibility and drug content. The tablets of the proposed formulations (F-1 - F-7) were subjected to various evaluation tests like thickness, hardness, weight variation test and friability (Table 4). The thickness of the tablets ranged from $4.05 \pm 0.10$ to $4.88 \pm 0.03 \mathrm{~mm}$. The 
hardness and percentage friability of the tablets of all the formulations ranged from $5.0 \pm 0.02$ to $8.1 \pm 0.04$ $\mathrm{kg} / \mathrm{cm}^{2}$ and $0.05 \pm 0.04$ to $0.50 \pm 0.01 \%$, respectively. The average percentage deviation of 20 tablets of each formula was less than $\pm 5 \%$. Drug content among different batches of tablets ranged from 96.03 \pm 0.05 to $102.65 \pm 0.02 \%$. In a weight variation test, the pharmacopoeial limit for the percentage deviation for tablets was $\pm 0.5 \%$. Good uniformity in drug content was found among different batches of the tablets, and the percentage of drug content was more than $96 \%$. In this study, the percentage friability for all the formulations was below $1 \%$, indicating that the friability was within the official limits. All the tablet formulations showed acceptable pharmacotechnical properties and complied with the in-house specifications for weight variation, drug content, hardness and friability. The proposed formulation F-3 (using 40\% Methocel K100M of the total wt. of tablet) and F-4 (using 45\% Methocel $\mathrm{K} 100 \mathrm{M}$ of the total wt. of tablet) exhibited official (USP) drug release than other formulations for $24 \mathrm{~h}$ period. This drug release pattern was compared with the originator brand of Arrestin SR (Maneesh Pharma, India) and found to be similar to each other (Figure 6). Among these formulations, the rate and extent of drug release was decreased with increasing the amount of Methocel K100M. This polymer has been well known to retard the drug release by swelling in aqueous media. A polymer's ability to

Table 4. Physical properties of Aceclofenac SR matrix tablets (F-1 to F-7).

\begin{tabular}{|c|c|c|c|c|c|}
\hline Tablets & $\begin{array}{c}\text { Thickness } \\
\text { (mm) }\end{array}$ & $\begin{array}{c}\text { Weight Variation } \\
(\%)\end{array}$ & Drug Content (\%) & $\begin{array}{l}\text { Hardness } \\
\left(\mathrm{Kg} / \mathrm{cm}^{2}\right)\end{array}$ & $\begin{array}{l}\text { Friability } \\
(\%)\end{array}$ \\
\hline F-1 & $4.10 \pm 0.02$ & $1.50 \pm 0.02$ & $98.07 \pm 0.05$ & $6.50 \pm 0.03$ & $0.25 \pm 0.01$ \\
\hline $\mathrm{F}-2$ & $4.88 \pm 0.003$ & $2.20 \pm 0.02$ & $96.03 \pm 0.05$ & $6.02 \pm 0.03$ & $0.50 \pm 0.01$ \\
\hline F-3 & $4.75 \pm 0.03$ & $4.20 \pm 0.03$ & $98.07 \pm 0.05$ & $6.50 \pm 0.03$ & $0.25 \pm 0.01$ \\
\hline F-4 & $4.50 \pm 0.02$ & $2.75 \pm 0.01$ & $102.65 \pm 0.10$ & $5.00 \pm 0.02$ & $0.33 \pm 0.01$ \\
\hline F-5 & $4.05 \pm 0.10$ & $1.20 \pm 0.05$ & $98.07 \pm 0.03$ & $6.50 \pm 0.03$ & $0.49 \pm 0.01$ \\
\hline F-6 & $4.10 \pm 0.01$ & $1.50 \pm 0.02$ & $102.65 \pm 0.02$ & $6.50 \pm 0.03$ & $0.25 \pm 0.01$ \\
\hline F-7 & $4.05 \pm 0.10$ & $1.50 \pm 0.02$ & $96.03 \pm 0.05$ & $8.1 \pm 0.04$ & $0.05 \pm 0.04$ \\
\hline
\end{tabular}

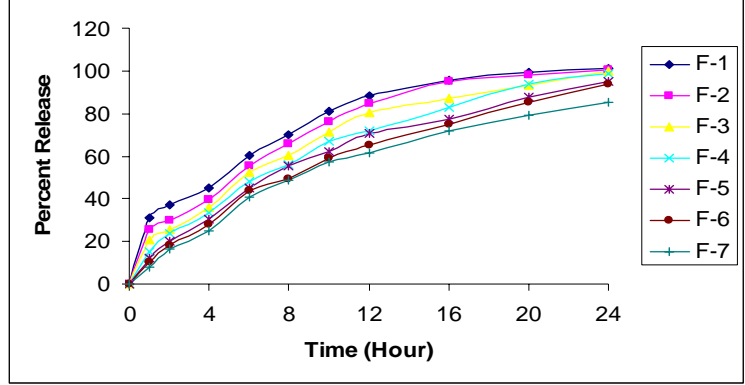

Figure 1. Zero order plot of release kinetics of Aceclofenac SR tablets.

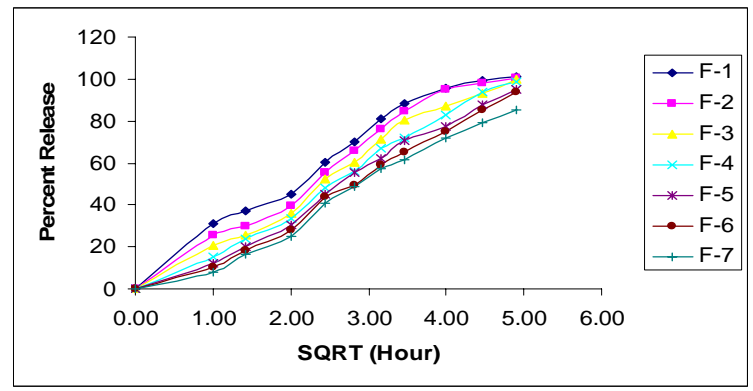

Figure 2. Higuchi plot of release kinetics of Aceclofenac SR tablets.

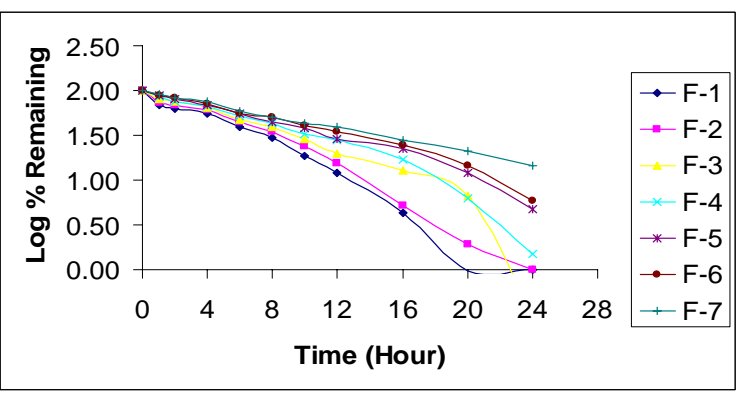

Figure 3. First order plot of release kinetics of Aceclofenac SR tablets.

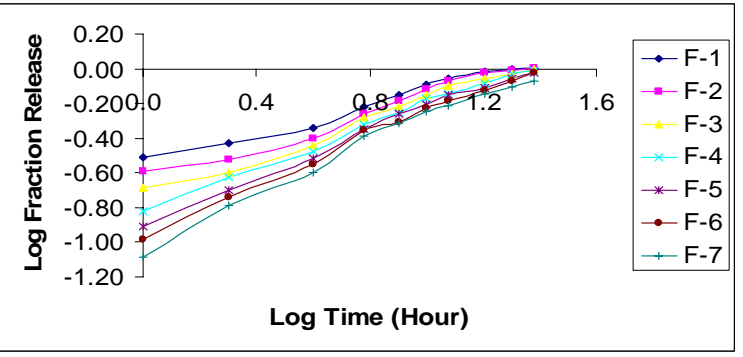

Figure 4. Korsmeyer plot of release kinetics of Aceclofenac SR tablet. 


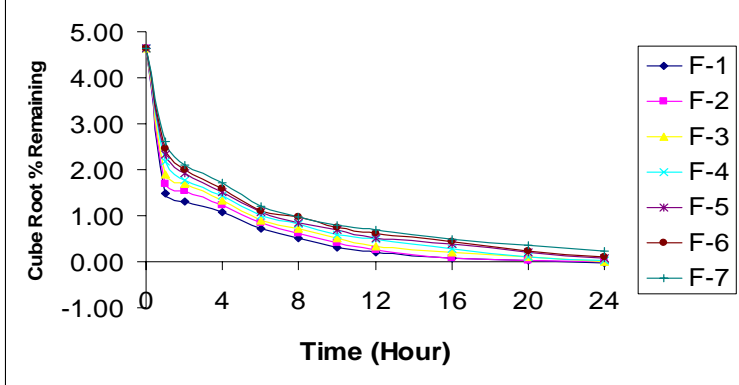

Figure 5. Hixson-Crowell plot of release kinetics of Aceclofenac SR tablets.

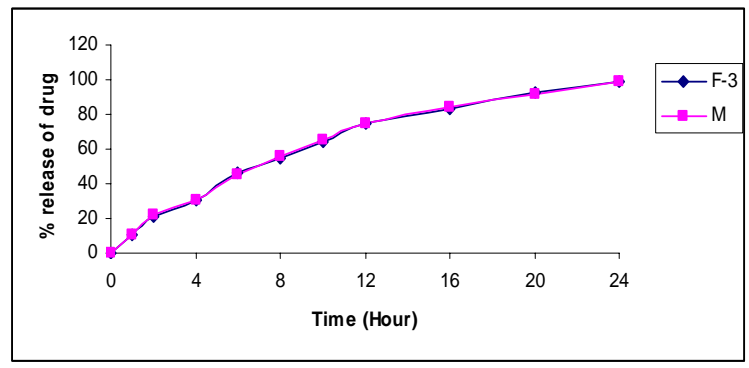

Figure 6. Comparison of release kinetics of F-3 and commercial brand Arrestin SR. retard the drug release rate is related to its viscosity. However, processing factors including particle size, hardness, porosity and compressibility index etc. also affect the release rate of drug from tablets. The hydration rate of HPMC depends on the nature of the substituent like hydroxypropyl group content. Hence, Methocel K100M CR was used because it forms a strong viscous gel in contact with aqueous media, which may be useful in controlled delivery of drugs. The drug release data obtained were extrapolated by Zero order, Higuchi, First order, Korsmeyer-Peppas and Hixson-Crowell equations to know the kinetics of drug release from these formulations (Table 5). In this experiment, the in vitro release profiles of drug from all these formulations could be best expressed by Higuchi's equation, as the relevant plots showed highest linearity ( $\mathrm{R}^{2}: 0.97$ to 0.99 ). To confirm the diffusion mechanism, the data were fitted into Korsmeyer-Peppas equation (Figure 4). The formulations showed good linearity $\left(\mathrm{R}^{2}: 0.97\right.$ to 0.99 ), with slope (n) values ranging from 0.605 to

Table 5. Interpretation of R-square values and rate constants for different release kinetics of formulations (F-1 to F-7).

\begin{tabular}{lllllllllll}
\hline \multirow{2}{*}{ Formulation } & \multicolumn{2}{l}{ Zero order } & Higuchi & \multicolumn{3}{c}{ First order } & \multicolumn{2}{c}{ Korsmeyer } & \multicolumn{2}{c}{ Hixson- Crowell } \\
\cline { 2 - 11 } & $\mathrm{K}_{0}$ & $\mathrm{R}^{2}$ & $\mathrm{~K}_{\mathrm{h}}$ & $\mathrm{R}^{2}$ & $\mathrm{~K}_{1}$ & $\mathrm{R}^{2}$ & $\mathrm{n}$ & $\mathrm{R}^{2}$ & $\mathrm{~K}_{\mathrm{HC}}$ & $\mathrm{R}^{2}$ \\
\hline F-1 & 4.08 & 0.90 & 22.46 & 0.98 & -0.088 & 0.93 & 0.605 & 0.98 & -0.130 & 0.58 \\
F-2 & 4.09 & 0.92 & 22.34 & 0.98 & -0.076 & 0.93 & 0.654 & 0.99 & -0.133 & 0.61 \\
F-3 & 4.07 & 0.93 & 21.98 & 0.99 & -0.067 & 0.93 & 0.703 & 0.99 & -0.135 & 0.63 \\
F-4 & 3.94 & 0.94 & 21.29 & 0.99 & -0.054 & 0.95 & 0.716 & 0.99 & -0.134 & 0.64 \\
F-5 & 3.76 & 0.94 & 20.24 & 0.98 & -0.042 & 0.98 & 0.722 & 0.99 & -0.133 & 0.65 \\
F-6 & 3.58 & 0.93 & 19.39 & 0.97 & -0.035 & 0.98 & 0.737 & 0.98 & -0.131 & 0.64 \\
F-7 & 3.44 & 0.94 & 18.42 & 0.97 & -0.030 & 0.99 & 0.820 & 0.97 & -0.133 & 0.67 \\
\hline
\end{tabular}

0.820 , indicating that diffusion as well as erosion were the predominant mechanisms of drug release from these formulations. When plotted according to Korsmeyer-Peppas equation, the formulations F-3, F-4 and F-5 showed high linearity ( $\left.\mathrm{R}^{2}: 0.99\right)$, with a comparatively high slope (n) values of $>0.6$, which appears to indicate a coupling of diffusion and erosion mechanisms (Table 2). Hence, diffusion coupled with erosion might be the mechanism for the drug release from Methocel K100M CR based matrix tablet. The release profile of Aceclofenac from all these formulations displayed very poor fitting with Hixson-Crowell cube root model of drug release which were related with the method of manufacture followed (Figure 5).

\section{CONCLUSION}

In order to achieve patient compliance for the management of different types of pain, formulation of once daily Aceclofenac tablet is essential. Hydrophilic polymer particles have unique quality to hold drug firmly through matrix formation while compressed into tablet. This matrix promotes desired controlled drug release upon hydration, swelling and gel formation when interact with gastrointestinal fluid. Methocel K100M CR based formulation F-3 
fulfilled the official release requirement and comparable with originator brand Arrestin SR (Fig6). Thus, the proposed formulation F-3 can be successfully used for commercial production because it was stable under accelerated stability condition.

\section{ACKNOWLEDGMENTS}

The authors would like to acknowledge the Chairman, Department of Pharmaceutical Technology, and Director, Centre for Advanced Research in Sciences, University of Dhaka, Dhaka, Bangladesh, for providing the facilities to carry out this study.

\section{REFERENCES}

1. Sean, C.S., 6/2002. (ed). Martindale: The Extra Pharmacopia (electronic version). Micromedex, Inc, Denver, CO, Vol. 104 expires.

2. Balleteros, R., Ansoleaga, J.J., Tapounet, R. 1990. The efficiency and tolerance of Aceclofenac in rheumatoid arthritis. Clin. Tech. J. 27, 12-19.

3. Reynolds, J.E.F. 2002. Martindale: The Extra Pharmacopia (electronic version). Micromedex, Inc, Denver, CO, Vol. 104 expires.

4. Hindustan, A. A., Chitta, S. K., Raghu,C.,Udhaya, B.T., Achuta, R., Abhilash. C., Vamsi, M.G. 2010. Formulation and Evaluation of Once-Daily Sustained Release Aceclofenac Prosopis cumanensis gum Matrix Tablets. JITPS. 1, 53-63
5. Reddy, R.K., Mutalik, S. and Reddy, S. 2003. Once daily sustained release matrix tablets of Nicorandil: formulation and in vitro evaluation. AAPS. PharmSciTech. 4, article 61

6. Ford, J.L., Rubinstein, M.H. and Hogan, J.E. 1985. Formulation of sustained-release promethazine hydrochloride tablets using hydroxypropyl methyl cellulose matrixes. Int. J. Pharm. 24, 327-338.

7. Hogan, J. 1989. Hydroxypropylmethylcellulose sustained release technology. Drug Dev. Ind. Pharm. 15, 975-999.

8. Santanu, G., and Barik, B.B. 2010. Formulation and in Vitro Evaluation of Once Daily Sustained Release Formulation of Aceclofenac. Trop. J. Pharm. Res.. 9, 265-273

9. Amidon, G.L. and Löbenberg, R. 2000. Modern Bioavailability, Bioequivalence and Biopharmaceutics Classification system. New Scientific Approaches to International Regulatory Standards. Eur. J. Pharm. Biopharm. 50, 3-12

10. Vazquez, M.J., Perez-Marco, Gomez- Amoza, J.L., MartinezPacheco, R., Souto, C. and Concheiro, A. 1992. Influence of technological variables on drug release of drug from hydrophilic matrices. Drug Dev. Ind. Pharm. 18, 1355-1375.

11. Aulton, M.E. and Wells, T.I. 1998.The Science of Dosage Form Design. London, England, Churchill Livingstone.

12. Harland, R.S., Gazzaniga, A., Sangalli, M.E., Colombo, P. and Peppas, N.A. 1988. Drug/polymer matrix swelling and dissolution. Pharm. Res. 5, 488-494. 